\title{
Effects of gelatin sponge combined with moist wound-healing nursing intervention in the treatment of phase III bedsore
}

\author{
${\text { YANLING } \mathrm{LI}^{1 *}, \text { MEIYING YAO }}^{2^{*}}, \mathrm{XIA} \mathrm{WANG}^{3}$ and YANQING ZHAO ${ }^{4}$ \\ Departments of ${ }^{1}$ Neurology and ${ }^{2}$ Nephrology, Liaocheng People's Hospital; ${ }^{3}$ Outpatient Office, Liaocheng Third People's \\ Hospital; ${ }^{4}$ Department of Cardiology, Liaocheng Third People's Hospital, Liaocheng, Shangdong 252000, P.R. China
}

Received February 10, 2016; Accepted March 24, 2016

DOI: 10.3892/etm.2016.3191

\begin{abstract}
Pressure sore pertains to tissue damage or necrosis that occurs due to lack of adequate nutrition following long-term exposure to pressure and decreased blood circulation. The aim of the study was to examine the effects of gelatin sponge combined with moist wound-healing nursing intervention in the treatment of phase III bedsore. In total, 50 patients with phase III bedsore were included in the present study. The patients were randomly divided into the control $(n=25)$ and observation $(n=25)$ groups. Patients in the control group received conventional nursing, while those in the observation group received gelatin sponge combined with moist wound healing nursing. The effects of the two nursing methods were compared and analyzed. The results showed that the improvement rate of the observation group was significantly higher than that of the control group $(\mathrm{P}<0.05)$. The Branden score and area of pressure sore of the observation group were significantly lower than those of the control group $(\mathrm{P}<0.05)$. The frequency and time of dressing change and the average cost of hospitalization of the observation group were significantly lower than those of the control group $(\mathrm{P}<0.001)$. In conclusion, gelatin sponge combined with moist wound-healing nursing intervention may significantly improve the treatment of phase III bedsore.
\end{abstract}

\section{Introduction}

Pressure sore refers to the tissue damage or necrosis that results from the lack of adequate nutrition caused by the body's long-term exposure to pressure and slacking blood circulation (1). Pressure sore is a common complication in patients with breast cancer (2). Major clinical treatments are traditional

Correspondence to: Dr Xia Wang, Outpatient office, Liaocheng Third People's Hospital, 6 Weiyu Road, Liaocheng, Shangdong 252000, P.R. China

E-mail: yfo969@163.com

*Contributed equally

Key words: gelatin sponge, wet healing nursing, phase III bedsore medicine and nursing intervention; however, the curative effects are not optimistic (3). In 1962, Dr Winter identified moist wound-healing nursing, which became widely used (4). Type I gelatin sponge has similar components with the connective tissues of the body. It can quickly promote tissue healing, realize rapid degradation, and has good biocompatibility characteristics; thus, it has been widely used in tissue engineering (4).

The aim of the present study was to examine the effects of gelatin sponge combined with moist wound-healing nursing intervention in the treatment of phase III bedsore.

\section{Materials and methods}

Materials. A total of 50 patients with phase III bedsore, treated at the Liaocheng People's Hospital between March 2013 and July 2014 were included in the study. All the patients conformed to the diagnostic criteria suggested by the National Pressure Ulcer Advisory Panel Society: entire skin defect without muscles, tendons or bones exposed, with or without incrustation and subcutaneous tunnel (6). Approval for the study was obtained from the ethics committee of Liaocheng People's Hospital. Informed consent was obtained from the patients and/or relatives.

The patients were randomly divided into the control $(n=25)$ and observation $(n=25)$ groups. The patient age range for the control group was 59-80 years, with an average of $68.0 \pm 6.5$ years. In control group, 31 pressure sores were located in sacroiliac, 11 pressure sores in hip joint and 8 in ankle and foot. The Branden scores ranged from 10 to 22 points, with an average of $14.0 \pm 3.2$ points, and the area of pressure sore ranged from $(2 \times 1 \mathrm{~cm})$ to $(10 \times 8 \mathrm{~cm})$. Concerning the observation group, the patient age range was 56-82 years, with an average age of $67.9 \pm 7.2$ years. In those patients, 33 pressure sores were located in sacroiliac, 10 pressure sores in hip joint and 6 in ankle and foot. The Branden scores ranged from 11 to 24 points, with an average of $15.3 \pm 3.5$ points, and the area of pressure sore ranged from $(1.5 \times 1.5 \mathrm{~cm})$ to $(10.5 \times 7.5 \mathrm{~cm})$. The differences in age, pressure sore sites, Branden score and area of pressure of the two groups were not statistically significant $(\mathrm{P}>0.05)$.

Nursing methods. Patients in the control group were provided conventional nursing care. Hydrogen peroxide or iodine was used for local disinfection and mechanical debridement to 
Table I. Comparison of healing effects.

\begin{tabular}{|c|c|c|c|c|c|c|}
\hline Group & Case & Excellence $^{\mathrm{a}}$ & Effective $^{\mathrm{b}}$ & Ineffective $^{c}$ & Deterioration $^{\mathrm{d}}$ & Improvement rate $(\%)$ \\
\hline Observation & 25 & 10 & 13 & 2 & 0 & 92.0 \\
\hline Control & 25 & 8 & 9 & 5 & 3 & 68.0 \\
\hline$\chi^{2}$ & & & & & & 4.500 \\
\hline P-value & & & & & & 0.034 \\
\hline
\end{tabular}

${ }^{a}$ Excellence, total PUSH scores of 0 point, wound and epithelium were healed; beffective, total PUSH scores decreased, surrounding skin and granulation had no significant abnormality; cineffective, total PUSH scores and the wounds before and after treatment had no change; ${ }^{d}$ deterioration, total PUSH scores increased, the surrounding skin was festered, the color was deepened and secondary infection appeared. PUSH, Pressure Ulcer Scale for Healing.

Table II. Comparison of the Branden scores and area of pressure sore.

\begin{tabular}{|c|c|c|c|c|}
\hline \multirow[b]{2}{*}{ Group } & \multicolumn{2}{|c|}{ Branden scores } & \multicolumn{2}{|c|}{ Area of pressure sore $\left(\mathrm{cm}^{2}\right)$} \\
\hline & Pretreatment & Post-treatment & Pretreatment & Post-treatment \\
\hline Observation & $14.6 \pm 3.5$ & $7.8 \pm 1.9$ & $32.4 \pm 10.5$ & $16.9 \pm 4.2$ \\
\hline Control & $13.8 \pm 2.3$ & $11.4 \pm 3.1$ & $33.7 \pm 8.2$ & $27.1 \pm 6.3$ \\
\hline t-test & 0.634 & 4.914 & 0.539 & 5.561 \\
\hline P-value & 0.837 & 0.032 & 0.916 & 0.025 \\
\hline
\end{tabular}

remove the purulent secretion of necrotic tissues, and ethacridine gauze was used to fill in the potential lacuna of the lacunar pressure sore. Aseptic dressing was used to cover the wound, and the dressing was changed once every 1-2 days.

The patients in the observation group received gelatin sponge combined with moist wound-healing nursing. The normal saline or cotton ball was used to clean the wound surface. The yellow wound surface (if any) was cleaned with surgical debridement (blade, or sterile scissors) to excise the necrotic tissues and the gelatin sponge to absorb seepage and cover the wound. In case of infection, gelatin sponge was soaked with silver ion alginate (Kanglebao Company, Guangzhou, China) was used to cover the yellow surface and the skin in or around the dressing was closely examined. If there was seepage and the milk white area was $>1 / 3$, the sponge (once/1-2 days) was changed in a timely manner after new granulation tissues appeared on the sponge. The area was washed again to apply the gelatin sponge once per week. Humanized nursing was strengthened gently and the patients were slowly turned over once every $2 \mathrm{~h}$ by elevating the bedside to maintain an angle within $30^{\circ}$ to prevent exertion of excessive force on the sacral tail. The patients were kept dry and smooth, and an air cushion bed comprehensively improved the nutritional status of the patients. Subsequently, the patients were followed up and provided with health education prior to discharge from the hospital. Additionally, the patients and their families were informed of the risk factors of pressure sores.

Observation indices and evaluation standard. At 28 days later, the healing state of patients was closely examined including the curative effects, frequency of dressing change
Table III. Comparison of frequency and time of dressing change, and costs.

\begin{tabular}{lccc}
\hline Group & $\begin{array}{c}\text { Frequency } \\
\text { (times) }\end{array}$ & $\begin{array}{c}\text { Time } \\
(\mathrm{min})\end{array}$ & $\begin{array}{c}\text { Average costs } \\
\text { (yuan) }\end{array}$ \\
\hline Observation & $7.8 \pm 0.9$ & $20.9 \pm 8.4$ & $2675.4 \pm 234.5$ \\
Control & $16.2 \pm 2.7$ & $31.8 \pm 12.6$ & $7826.5 \pm 1342.1$ \\
t-test & 4.316 & 4.813 & 6.809 \\
P-value & 0.039 & 0.037 & $<0.001$ \\
\hline
\end{tabular}

and efficiency of end point. The quantitative scoring was performed according to Pressure Ulcer Scale for Healing (7) compiled by the US pressure sore expert group and the curative effects were evaluated (Table I).

Statistical analysis. SPSS 19.0 statistical software (SPSS, Inc., Chicago, IL, USA) was used for statistical analysis and data were presented as mean \pm standard deviation. The comparison between the groups was made using the t-test. The enumeration data were expressed by percentage (\%). A comparison between groups was made using the $\chi^{2}$ test. $\mathrm{P}<0.05$ was considered to indicate a statistically significant difference.

\section{Results}

Comparison of healing effects. The improvement rate of the observation group $(92.0 \%)$ was significantly higher than that of the control group $(68.0 \%)$ (Table I; $\mathrm{P}<0.05)$. 
Comparison of Branden scores and area of pressure sore. Prior to treatment, the Branden score and area of pressure sore of the control and observation groups were not statistically different $(\mathrm{P}>0.05)$. Following treatment, the Branden score and area of pressure sore of the observation group were significantly lower than those of the control group $(\mathrm{P}<0.05$; Table II).

Comparison of frequency and time of dressing change, and costs. The frequency, time of dressing change and average costs of hospitalization of the observation group (7.8 \pm 0.9 , $20.9 \pm 8.4$, and $2675.4 \pm 234.5$, respectively) were significantly lower than those of the control group $(16.2 \pm 2.7,31.8 \pm 12.6$, and $7826.5 \pm 1342.1$, respectively) $(\mathrm{P}<0.001)$ as shown in Table III.

\section{Discussion}

Traditional cleaning, disinfection and other commonly used medical gauze, due to their poor moisture absorption, cannot be degraded in vivo and the prescription contains light powder that is toxic to liver and kidney (8). Gelatin sponge effectively absorbs the tissue fluid, and is favorable for local hemostasis. It can absorb water of 50 -fold and blood of 48 -fold its own weight. After absorbing a large amount of blood, gelatin sponge can promote the rupture of platelet, release a large number of platelet coagulation factors and promote blood coagulation (9). In addition, gelatin sponge supports the blood block to prevent it from decreasing, resulting in anastalsis (10). The gelatin sponge became jelly-like one week following application and was completely absorbed after 1-2 months. It could be left in the body and did not produce any antigenicity, excessive scar tissues or fibrotic reactions (11). Gelatin sponge is a also good drug carrier. Previous findings have shown that it promoted wound surface healing compared to the external application of Chinese medicine or gauze (12).

In the present study, the importance of moist healing nursing was also emphasized. Other studies on wound surface have confirmed that dryness can aggravate the degree of tissue damage while moisture was more favorable for the wound surface healing (13). Moisture can promote and accelerate natural healing and the healing speed in the moisture environment is faster than the dry environment. For the pressure sores of patients with breast cancer, the optimal way in which to restore the damaged epithelial tissues is to seal the moist wound, promote the growth of keratinocytes of the wounds and elevate the regenerative velocity by $40 \%$ (14). A moist environment is advantageous to the adhesion of dressing and wound surface, and would not damage the granulation tissue or wound epithelial tissue, relieving pain experienced by the patients (15).

Patients of the control group received sterile gauze caring. During dressing, gauze dressing was likely to adhere to the surface of the wound, rendering it unfavorable for seepage absorption, and excessive seepage also required frequent change of gauze. Patients of the observation group were provided with gelatin sponge caring, which effectively improved the absorption effects of seepage, kept the area of pressure sore in a closed space and avoid invasion and infection of external microorganisms (16). Patients of the observation group were also assisted by humanized nursing, such as psychological guidance and health education (17), and had nurse assistance in being turned over once every $2 \mathrm{~h}$ and keeping their skin smooth and dry. The above measures constitute a good treatment environment for breast cancer patients with pressure sores (18).

The results of the present study have shown that the improvement rate of the observation group was significantly higher than that of the control group, The Branden score and the area of pressure sore were significantly lower than those of the control group, and frequency and time of dressing change and average cost of hospitalization were significantly lower than those of the control group. These differences were statistically significant, thereby greatly reducing the workload of nursing personnel (19). In conclusion, gelatin sponge combined with moist wound-healing nursing intervention may significantly improve the healing of phase III bedsore.

\section{References}

1. Woo KY, Sears K, Almost J, Wilson R, Whitehead M and VanDenKerkhof EG: Exploration of pressure ulcer and related skin problems across the spectrum of health care settings in Ontario using administrative data. Int Wound J: Nov 20, 2015 (Epub ahead of print).

2. Palagi S, Severo IM, Menegon DB and Lucena AF: Laser therapy in pressure ulcers: Evaluation by the pressure ulcer scale for healing and nursing outcomes classification. Rev Esc Enferm USP 49: 826-833, 2015.

3. Fulbrook P and Anderson A: Pressure injury risk assessment in intensive care: comparison of inter-rater reliability of the COMHON (Conscious level, Mobility, Haemodynamics, Oxygenation, Nutrition) index with three scales. J Adv Nurs 72: 680-692, 2016.

4. Winter GD: Formation of the scab and the rate of epithelization of superficial wounds in the skin of the young domestic pig. Nature 193: 293-294, 1962.

5. Sullivan R: Use of a soft silicone foam dressing to change the trajectory of destruction associated with suspected deep tissue pressure ulcers. Medsurg Nurs 24: 237-242, 267, 2015.

6. Lyder CH: A lively conference with plenty of debate for the NPUAP in Texas. J Wound Care 16: 207-208, 2007

7. Choi EP, Chin WY, Wan EY and Lam CL: Evaluation of the internal and external responsiveness of the Pressure Ulcer Scale for Healing (PUSH) tool for assessing acute and chronic wounds. J Adv Nurs: Jan 11, 2016 (Epub ahead of print).

8. Moore ZE, Webster J and Samuriwo R: Wound-care teams for preventing and treating pressure ulcers. Cochrane Database Syst Rev 9: CD011011, 2015.

9. Balzer K and Kottner J: Evidence-based practices in pressure ulcer prevention: Lost in implementation? Int J Nurs Stud 52: 1655-1658, 2015.

10. Santos CT, Almeida Mde A, Oliveira MC, Victor MA and Lucena Ade F: Development of the nursing diagnosis risk for pressure ulcer. Rev Gaucha Enferm 36: 113-121, 2015 (In Portuguese).

11. McInnes E, Jammali-Blasi A, Bell-Syer SE, Dumville JC, Middleton V and Cullum N: Support surfaces for pressure ulcer prevention. Cochrane Database Syst Rev 9: CD001735, 2015.

12. Sardo P, Simões C, Alvarelhão J, Costa C, Simões CJ, Figueira J, Simões JL, Amado F, Amaro A and Melo E: Pressure ulcer risk assessment: Retrospective analysis of Braden Scale scores in Portuguese hospitalised adult patients. J Clin Nurs 24: 3165-3176, 2015.

13. Varga M: Prioritizing pressure ulcer prevention. Alta RN 71: 26-27, 2015.

14. Marsden G, Jones K, Neilson J, Avital L, Collier M and Stansby G: A cost-effectiveness analysis of two different repositioning strategies for the prevention of pressure ulcers. J Adv Nurs 71: 2879-2885, 2015. 
15. Waugh SM: Attitudes of nurses toward pressure ulcer prevention: A Literature Review. Medsurg Nurs 23: 350-357, 2014.

16. Karopchinsky JA: Pressure ulcers. Medsurg Nurs 24: 183-184, 2015.

17. Kaitani T, Nakagami G, Iizaka S, Fukuda T, Oe M, Igarashi A, Mori T, Takemura Y, Mizokami Y, Sugama J, et al: Cost-utility analysis of an advanced pressure ulcer management protocol followed by trained wound, ostomy, and continence nurses. Wound Repair Regen 23: 915-921, 2015.
18. Demarré L, Van Lancker A, Van Hecke A, Verhaeghe S, Grypdonck M, Lemey J, Annemans L and Beeckman D: The cost of prevention and treatment of pressure ulcers: A systematic review. Int J Nurs Stud 52: 1754-1774, 2015.

19. Akese MI, Adejumo PO, Ilesanmi RE and Obilor HN: Assessment of nurses' knowledge on evidence-based preventive practices for pressure ulcer risk reduction in patients with impaired mobility. Afr J Med Med Sci 43: 251-258, 2014. 